\section{New Journals review 1992}

CRITERIA for journals to be considered for review in this issue were circulated to publishers earlier this year, and were also published in Nature. They were that:

(1) the first number appeared during or after June 1990 and at least four separate numbers were issued by the end of April 1992 (although some of the journals not covered in last year's review issue were also considered)*;

(2) the journal is published at least three times a year;

(3) the main language used is English;

(4) where possible, at least four issues should be made available for review, including the first and the most recent numbers.

The time criteria ensure that a reasonable sample of issues is available for judgement by the time reviews are commissioned in June.

Several journals known to satisfy the above criteria were not submitted for review, or arrived too late for inclusion. It proved difficult to find reviewers for other, doubtless worthy journals, while some titles were considered to be of marginal interest to Nature's audience. Journals covering any aspect of science were eligible, although those dealing with clinical medicine, engineering and pure mathematics were excluded, as were abstracts publications and newsletters. A list of titles eligible for review but not covered appears on page 464 .

The brief given to the reviewers was to limit themselves to comments on the publications sent to them, and to avoid discussion of general questions of periodical publishing. Opinions expressed in the reviews are based on a sample of issues, and apply to mid-1992 at the latest. As in previous years, the preponderance of journals in the biological sciences reflects the bias of material submitted for review.

Details of editors and frequency of publication, and the subscription rates appearing at the top of each review, are given in most instances for 1992. This information is not complete in all cases, and readers interested in subscribing to a particular journal should check the rate with the publisher concerned.

* See Nature 353, 457-481 (1991); 347 581-599 (1990); 341, 350-370 (1989); 335, 459-478 (1988); 329, 357-376 (1987); 323, 359-379 (1986); 317, 293-308 (1985); 311, $309-330$ (1984); 305, 477-497 (1983); and 299, 491-514 (1982).

\title{
Bringing it all back home
}

James Lovelock

Science Probe! The Amateur Scientist's Journal. Editor Forrest M. Mims III. Science Probe Inc., 500-B Bi-County Boulevard, Farmingdale, New York 11735, USA. 12/yr. US \$11.95, Canada \$16.95, elsewhere $\$ 19.45$.

DID you see those violet coloured skies that followed sunset after the volcano $\mathrm{El}$ Chichón erupted in the early eighties, the visible expression of a stratospheric aerosol of volcanic sulphuric acid? Last year, the volcano Pinatubo injected an even larger mass of sulphur into the stratosphere but I have looked in vain for colourful night skies. It seems odd that millions of tons of sulphur dioxide suspect, of real value also to the professional. It bears such treasures as the telephone number through which to obtain graphic images, in a format compatible with your personal computer, from the Hubble telescope; how to make an electrocardiogram; and how to encounter slime moulds in their natural habitat. It is transdisciplinary and regards all science as open to the amateur.

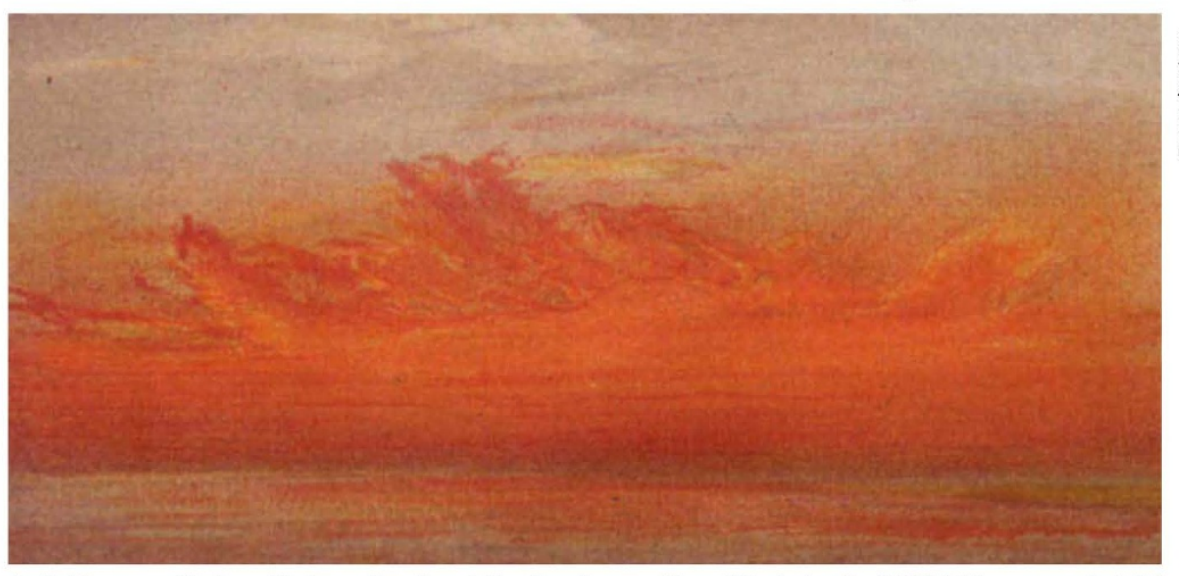

Red skies over Chelsea Harbour, London, following the eruptlon of Krakatoa in 1883. This crayon sketch is one of a series made shortly after sunset on 26 November 1883 by W. Ascroft.

injected into the stratosphere by one volcano in the northern tropics make colours visible in the sky in western Europe, but an even larger quantity from another volcano does not. I find it odder still that neither the journals of science nor the news media have commented on the colours of the night sky since the eruption of Pinatubo. Perhaps they think sunsets are just for poets.

Pinatubo and the night sky were covered in the new magazine Science Probe!. An informative article answered many of my questions, and even showed how to estimate the height of the aerosol layer from the length of time colours lingered after sunset. This journal brings back a world of which science was a familiar part. For me it recalled an altogether lighter and more friendly $\mathrm{Sci}$ entific American, read with joy in the public library at Brixton, south London, 60 years ago. Such reading and amateur experiments led me to a fulfilling life in the vocation of science, reading that was the antidote to the scientifically correct but utterly dull teaching of my grammar school. Science taught then, as now, was mere knowledge needed to pass exams.

Science Probe! is a cornucopia of delights for the amateur scientist and, I
In her clear and concisely written article, Valerie Villarreal, a high-school student, describes her project, "The Role of Capsaicin in Carcinogenesis". In another article, Mark Hartwig makes basic statistics so lucid that some professional scientists who read it may be able to distinguish precision from accuracy.

Science is criticized by some philosophers as soulless and damaging. This may be true of that part of science which has become too serious, narrowly specialized and subject to the strictures of scientific correctness; or of competitive fields, such as AIDS research, that are flawed, like the Olympics, by hubris. Science has lost soul; who would want to do chemistry for fun in the all-too-safe laboratory today? How did we allow dogma to become respectable and speculation pejorative? I grew up in science thinking that our task was to reduce science fiction to practice and have done my best to do so. I hope that Science Probe! flourishes and brings back science as something interesting that can be done at home.

James Lovelock is at Coombe Mill, St Giles on the Heath, Launceston PL15 9RY, UK. 